\title{
A gradient approach to flexible constituent order
}

\author{
Savithry Namboodiripad \\ University of Michigan, Ann Arbor \\ Address \\ savithry@umich.edu
}

\begin{abstract}
Languages are known to differ in how many orderings of major constituents are grammatical, as well as how interchangeable these orders are, a property often referred to as FLEXIBILITY. Due to a variety of factors, including methodological barriers, flexibility is often underdescribed or treated as categorically, with languages being placed into heterogenous bins such as "free" or "rigid". This paper advocates for starting from the premise that languages differ in degree and not kind when it comes to flexibility, presents a novel method for measuring flexibility in constituent order (via acceptability judgment experiments), and applies this approach to two languages which are known to differ in flexibility: English (Experiment 1) and Malayalam (Experiment 2). Flexibility is operationally defined as the difference in acceptability between canonical and non-canonical orders. Experiment 1 demonstrates that acceptability experiments can distinguish between canonical (svo), non-canonical (osv), and ungrammatical orders in English. For Malayalam, in which all orders of subject, object, and verb are grammatical and attested, verb-final orders group together and are most acceptable, followed by verb-medial and then verb-initial orders; this provides an initial picture of non-verb-final orders, which have been under-theorized in this language. Finally, a qualitative comparison of each language's CONSTITUENT ORDER PROFILE (a plot of the acceptability of each order in a language) serves as proof-of-concept that this measure allows for meaningful comparison across languages. This approach serves to enrich typological descriptions of constituent order across languages, and it opens up opportunities for testing hypotheses about the source(s) of flexibility.
\end{abstract}

Keywords: flexible constituent order, typology, acceptability judgment experiments, Malayalam, English 


\section{Typological variation in flexible constituent or- der}

Major constituent order, the relative ordering of SUBJECT, OBJECT, and VERB, is among the most well-researched areas in syntactic typology. The canonical (discourse-neutral, intonationally unmarked, basic) constituent order is often the first entry in the "Syntax" section of a language's grammar, making constituent order a natural entry point for the linguist interested in typology. As such, there is a long history of inquiry from multiple theoretical and methodological perspectives into the sources of cross-linguistic variation when it comes to canonical constituent order (e.g., Hall 2012; Sinnemäki 2011; Dryer 2007; Mithun 1995). From a descriptive standpoint, the World Atlas of Language Structures (WALS) divides all languages into groups based on the "dominant" order, which is the most frequent ordering of constituents in declarative transitive sentences which have overt nonpronominal arguments (Dryer 2013). This divides the world's languages into eight groups: one group for each of the six logical orderings of constituents (SOV, OSV, SVO, OVS, VSO, VOS), one for languages which have two dominant orders, and one for languages which have been described as having no dominant order. Table 1 provides a summary of this.

Table 1: Languages divided by dominant order, from WALS online.

\begin{tabular}{|c|c|}
\hline GROUP & NUMBER OF LANGUAGES \\
\hline \hline SOV & 565 \\
\hline OSV & 4 \\
\hline SVO & 488 \\
\hline OVS & 11 \\
\hline VSO & 95 \\
\hline VOS & 25 \\
\hline TWO DOMINANT ORDERS & 67 \\
\hline NO DOMINANT ORDER & 189 \\
\hline
\end{tabular}

Of course, dominant order is but one way to divide the world's languages by constituent order: another dimension along which languages differ is FLEXIBILITY. Intuitively, flexibility translates to the degree to which constituents can appear in various orders; a language is more flexible if more orders are possible, and/or if order seems not to be tied closely to a particular discourse context. The distributions of languages reflected in Table 1 , 
which is widely used as a descriptive starting point for work on constituent order, was not intended to capture this. For example, both English and Russian are members of the 488 svo languages, and so are in the same category in Table 1 . However, all of the six logical orderings of constituents in Russian are grammatical and have the same truth-conditional meaning, and non-canonical orders are relatively frequent (Bailyn 2012). In English, on the other hand, only two of the six logical orderings of constituents are grammatical and have the same truth-conditional meaning; sVo and osv, the latter of which is relatively restricted, to the extent that it has been taken up in some contexts as a sociolinguistic variable (Prince 1988). Somewhat similar to Russian, all of the six orders of constituents are attested and relatively frequent in Warlpiri (Swartz 1988; Hale 1983), which belongs to the group of 189 languages which have no dominant order in Dryer's typology. In terms of flexibility, is Russian more like Warlpiri or English? How do languages differ in this domain?

This paper proposes and motivates a novel measure of flexibility using formal acceptability judgment experiments. I apply this measure to two languages which are known to differ in terms of flexibility, Malayalam (as spoken by young educated people in the central part of Kerala, India) and English (Mainstream United States English, or MUSE, as spoken by young educated people in the United States). The results of these experiments show that this measure captures known differences between these languages, and, in the case of Malayalam, provides new insight into the structure of the language. I argue that this measure enriches our current typological descriptions of constituent order, and, though flexibility has been connected to a variety of other empirical domains (like case-marking and head-finality), I claim that an independent and gradient measure of flexibility is a crucial component of any causal model of diachronic change and synchronic variation in constituent order. ${ }^{1}$

\subsection{Characterizing flexibility in constituent order}

One family of approaches to describing how languages differ in terms of constituent order flexibility has to do with asking where in a particular lan-

1 n.b. The empirical domain of this paper is the order of the major clausal constituents in a language - SUBJECT, OBJECT, and VERB - as opposed to an investigation of word order in general, which would also include the ordering of words within noun phrases and verb phrases (e.g., Dunn et al. 2011). In addition, I use S(ubject), O(bject), and V(erb), as is convention in some subdisciplines, but replacing these with A(gent), $\mathrm{P}$ (atient), and V(erb) would be equally appropriate. 
guage's grammar order is specified (or not). The question asked about each language is tied to the theoretical assumptions of the linguist: Does changing order change truth-conditional meaning? Is phrase structure used for the identification of core grammatical relations (Austin \& Bresnan 1996)? Is there scrambling (Karimi 2008)? Broadly speaking, this divides the world's languages into two groups: configurational or non-configurational, (Hale $1983)^{2}$, syntactically determined or pragmatically determined (e.g., Enfield 2009; Nordlinger 2006; Mithun 1995), and/or rigid or flexible (Dryer 2013).

A related approach asks: "How many orders are grammatical and have the same truth-conditional meaning?" This is exemplified in Siewierska \& Uhlirova (1998), which determines relative flexibility based on the number of grammatical orders in a language. Under this approach, languages like English and French, which only have one or two non-canonical grammatical orderings of constituents, are less flexible than languages like Bardi or Meskwaki, in which all six logical orders of SUBJECT, OBJECT, and VERB are grammatical and have the same truth-conditional meaning (Bowern 2008; Dahlstrom 2003). This approach divides the world's languages into six categories, depending on the number of grammatical orders, though the question of whether there are languages which have only one, three, or five grammatical orders is still open.

Heterogeneity within these categorical divisions has long been noted. Taking just two examples, Salzmann (2004) says "It should have become clear that non-configurationality is not a uniform phenomenon, ranging from rather superficial to deep non-asymmetries between subject and object" and Hale (1983) states "many languages present mixed testimony in the extent to which they exhibit the superficial characteristics of non-configurational languages." These categorical divisions are useful and have provided fruitful generalizations, but it is clear that, not only are there descriptive generalizations left to be captured, but more detailed descriptions could aid in understanding basic questions about constituent order. In particular, the underdescription of flexibility has been noted as an overlooked factor in historical reconstruction (Harris \& Campbell 1995) and determining the source and direction of contact effects (Thomason \& Kaufman 1988). To take one example, Harris \& Campbell (1995) write the following about reconstruction of constituent order:

2 Non-configurationality encompasses a variety of features, one of which is the existence of FREE WORD ORDER, which is defined in Hale (1992) as applicable to languages in which all of the six logical orderings of constituents are grammatically well-formed. 
"Scholars taking a typological approach to the study of diachronic change in word order have ofter overlooked one order, XY, occurring in dyads when the opposite order, YX, was predominant; this point has been made by Friedrich (1975) regarding typologically based reconstructions of Proto-IndoEuropean word order. [...] Watkins (1976:315-16) has pointed out that when all of the daughters give a strong indication of both orders, both must be reconstruction to the proto-language, but typologists have often not followed this practice. Ignoring some frequently occurring orders distorts the analysis as a whole."

When characterizing the heterogeneity of flexible languages, a fertile area of research has been to carefully identify the discourse conditions which license particular orders. The degree to which discourse context determines choice of constituent order varies cross-linguistically, and some languages like Bardi seem to be more permissive of the number of orders which are allowed in a particular discourse context than Tamil, in which non-verb-final orders are highly restricted (Bowern 2008; Herring 1994). So, languages like Bardi for which discourse context is less tied to a particular order (though order is still very much tied to discourse) would be considered to be "more free" as compared to languages like Tamil. The edited volume Pragmatics of Word Order Flexibility contains a variety of analyses of the discourse conditions which license orders in a wide range of languages, in particular focusing on the syntactic and cognitive-pragmatic factors which motivate variation in constituent order (Payne 2013).

Work on flexible constituent order in psycholinguistics builds on this tradition, asking about the prediction mechanisms and loci of processing effort in languages with variable constituent order, as well as investigating the relative contributions of syntactic and discourse-pragmatic factors in leading to differences in processing and/or acceptability between orders in a given language. ${ }^{3}$ This area of research has demonstrated that multiple factors are often at play; for example, Šimík \& Wierzba (2015) show that prosodic factors interact with other factors like givenness and definiteness in Czech. In this family of approaches, large-scale crosslinguistic comparison is not the goal, so asking the question of 'How many types of languages are there?' is not relevant. However, the measures used do allow for subtle differences in flexibility, which, as I posit here, has the potential to inform typological work.

${ }^{3}$ See Miyamoto \& Takahashi (2004) for Japanese and Kaiser \& Trueswell (2004) for Finnish 
Despite the known descriptive inadequacy of "flexibility" in constituent order, assumptions about the causal role of flexibility are present in a number of disciplines. Constituent order has been shown to be the highly borrowable aspect of language; areal effects are stronger for constituent order than would be explained by correspondences with head-marking, for example (Nichols 1992), and flexibility has been cited as facilitating borrowing in this domain (Aikhenvald 2003). However, much remains to be explored as to why it might be that constituent order is so easily borrowed and subject to change, how this occurs, and what the role of flexibility could be. In addition, theories about the evolution of language posit that proto-language could have been SOV (Givón 2014; Goldin-Meadow et al. 2008; Newmeyer 2000), but do not explicitly take into account flexibility, which could be very important for understanding basic questions about the depth of the relationship between order and argument structure. The implications for language contact, evolution, and change are beyond the scope of this paper; at this point, I simply note that further developing a notion of flexibility is necessary and relevant for a wide range of descriptive and theoretical reasons.

\subsection{A gradient approach}

The approach presented here complements and integrates the approaches described in the previous section, with the goal of first describing how flexibility varies across languages as a step towards eventually explaining the sources of this variation. This section concretizes the informal observed differences between languages in constituent order which have led to intuitions about heterogeneity in flexibility, asking how flexibility can be described in a cross-linguistically valid way. Specification of the intuitions serves to provide a bridge across the existing methods which have been used to compare flexibility in constituent order, which are mostly from elicitation and/or corpus methods or analyses of texts.

Below are two questions which underlie intuitions about relative flexibility in constituent order:

i. Which orders are possible?

ii. How good are these orders in relation to one another?

The extent to which a language is reliant on a particular order is intuitively related to its flexibility; the more a language relies on a particular order, the more rigid it is; this is another way of describing what people 
(both analysts and speakers) are paying attention to when they say, for example, that English is more rigid than Malayalam. Malayalam has more orders which can be used to describe the same event, and the orders which are less common do not seem as weird when compared with less common orders in English. I use the impressionistic term "weird" deliberately because it represents the intuition of interest quite literally - in many cases, linguists and speakers use this exact word or its translation. In languages with multiple grammatical orders, non-canonical orders are associated with different discourse contexts and, in some theoretical frameworks, syntactic representations. There are languages, like Korean, which allow all six logical orders in their grammar, but maybe two of those orders are very peripheral for speakers. This should be distinguished from languages where all orders have a similar status (like Latin) or only one non-canonical order is usually used (like English).

Let us consider how two extant methods of determining flexibility can answer these questions. Elicitation can answer the first question, of "which orders are possible". ${ }^{4}$ However, it can be very difficult for speakers to compare across sentence types which are very similar, and asking for relative judgments about six orders at once is challenging, though it can be done. Corpus studies or analyses of texts can tell us which orders are found, in addition to how frequent orders are relative to each other. However, genre/register almost always has a strong influence on which orders are used, and can overrepresent certain orders. More importantly for the interests of typological comparison, most languages lack corpora which are balanced enough to yield a definitive answer to "How good are these orders in relation to one another".

There certainly are other questions which are relevant to cross-linguistic comparisons; I highlight these because they present particular challenges. A pertinent example comes from Mithun (1992), in her comparison of speakers of Cayuga, Ngandi, and Coos to speakers of Czech. In all of these languages, all orderings of constituents are grammatical. Yet, there are differences, as she states:

Marta Roth informs me that Czech speakers, on the other hand [as compared to speakers of Cayuga, Ngandi, and Coos], are very conscious of "normal" word order. Alternate orders apparently do occur more frequently in Czech than in English.

4 Though see Thomason (2003) for examples of mis-documentation of flexible constituent order due to the challenges of elicitation. 
Yet when presented with these orders out of context, speakers are strongly aware of their marked status.

Mithun uses this observation as part of her argument problematizing the idea that "basic" word order is universal; this also demonstrates that it is relevant to ask about the relative status of different orders when comparing flexibility across languages. Asking "how good" about different constituent orders represents a crucial aspect of the approach proposed here: a move from assuming categorical variation across languages toward a gradient view by allowing languages to vary along a continuum of flexibility. The advantage to starting with the assumption of gradience $a$ priori is that we can let the data tell us whether or not languages vary along a continuum from more to less flexible; it could very well be that languages do fall into two or three categories, but asking categorical questions from the outset does not allow for the alternative to be true.

This brings me to the title of this paper, "A gradient approach to flexible constituent order": I do not address the issue of gradience in syntax within languages. This paper, rather, poses the question of whether languages might differ gradiently (that is, in degree and not kind) in constituent order flexibility and presents one method which can address that question. A potentially useful comparison could be with the relationship between Voicing and Voice Onset Time. Before careful phonetic measurements, the relevant phonological features were [+ VOICE] or [-VOICE]. This distinction captures very well variation within and across languages/varieties. However, with the discovery of VOT, we see that languages vary in a gradient manner. Though the binary distinction is still useful and important, having a notion of short-lag and long-lag enriches our typology and gets us closer to understanding co-articulatory effects and mechanisms of change. Similarly, categorizing languages as pragmatic or syntactic, or morphological or positional has given us a lot of descriptive power. However, a more gradient measure which is psycholinguistically grounded allows for the potential for large correlational studies which investigate the relationship between flexibility and other features such as case-marking, and, perhaps, could get us closer to understanding mechanisms of contact, emergence, and change. 


\section{Formal acceptability judgment experiments as a measure of flexibility}

The previous section argued for a gradient approach to flexible constituent order, and highlighted the inadequacy of relying on elicitation or corpus methods alone to answer questions about the relative "goodness" of orders. This section motivates formal acceptability judgment experiments as a measure of flexibility in constituent order. Decreased flexibility is defined as a greater preference for canonical as opposed to non-canonical orders, and I discuss the possibility that flexibility should be considered a property which varies in a gradient manner across languages. While this paper does not test enough languages to address typological questions, I present experiments in English and Malayalam, which serve as proof of concept that this measure can capture known differences in flexibility between languages, and which demonstrate of the utility of this measure in addressing previously undertheorized aspects of flexible constituent order.

Section 2.1 discusses some basic facts about constituent order in English and Malayalam, and Section 2.2 defines canonical order for the purposes of this approach. Finally, in Section 2.3, I discuss the relationship between lowered acceptability and non-canonical orders.

\subsection{English and Malayalam}

English and Malayalam are known to differ when it comes to constituent order, and this has been established via methods such as elicitation and speaker intuitions. As shown in (1), svo and OSV are the only two grammatical orders in English which describe an event where Leela is reading a book.
READ 〈Leela, book〉
a. "Leela a book read $\mathrm{SO} \mathrm{V}$
b. a book Leela read O S V
c. Leela read a book $S$ V O
d. *a book read Leela O V S 

e. *read Leela a book V S O
f. *read a book Leela V O S

In English, a change in order results in a change in truth-conditional meaning: Leela read a book means something different than a book read Leela. This is not the case in Malayalam; as shown in (2), all of the six logical orders are grammatical and can be used to describe the same event:

$$
\begin{aligned}
& \text { READ 〈Leela, book〉 } \\
& \text { a. li:la oru pustakam va:jitçu } \\
& \text { Leela a book read } \\
& \text { S O V, canonical } \\
& \text { b. oru pustakam li:la va:jitçu } \\
& \text { a book Leela read } \\
& \text { O S V } \\
& \text { c. li:la va:jitçu oru pustakam } \\
& \text { Leela read a book } \\
& \mathrm{S} \mathrm{V} \mathrm{O} \\
& \text { d. oru pustakam va:jitçu lisla } \\
& \text { a book read Leela } \\
& \mathrm{O} \text { V S } \\
& \text { e. va:jitçu lisla oru pustakam } \\
& \text { read Leela a book } \\
& \mathrm{VSO} \\
& \text { f. va:jitcu oru pustakam li:la } \\
& \text { read a book Leela } \\
& \text { V O S }
\end{aligned}
$$

Each sentence in (2) is attested, has the same truth-conditional meaning, and can be uttered within a single intonational contour; though the shape of the intonational contours varies across orders, each of these sentences can be uttered without a prosodic break (Leela 2016; Mohanan 1982). Note that Malayalam has differential object marking: subjects and inanimate objects are not overtly marked for case, so none of the Malayalam sentences discussed here have overt case-marking. In addition, verbs do not agree with subjects or objects.

Based on these examples, we can answer "Which orders are possible?" for each language, and, we can state intuitions about which orders are better. SVO and OSV are both grammatical in English, but these orders are 
not interchangeable. SVO is a less restricted order than OSV, in that it can appear in more contexts and is more frequent. For Malayalam, speakers have an intuition that SOV is the best order, and they are taught that this is the default order in school, but informal intuitions vary considerably when it comes to the other orders. In fact, as discussed in Section 4.1, syntactic accounts of non-verb-final orders in Malayalam vary, not just in the details of the analyses, but whether some of these orders are included at all. This is itself a sign that asking "How good?" about these other orders is relevant for accounts of constituent order in Malayalam and languages like it.

\subsection{Defining canonical order}

The notion of canonical order used here is not the same as underlying order (e.g., Barbiers (2000) and others who argue that English is underlyingly sov with short verb movement.), nor is it the most frequent order in a language: The canonical order in a language is often the most frequent, but not always, and what order counts as canonical can vary based on the register or syntactic context. As such, it is necessary to have definition that does not rely solely on frequency. I use a definition drawing from the notion of 'basic' order from Jackendoff (1972): A sentence is in canonical order if each constituent is able to take the role of the focus, where focus is defined as as any new, asserted, or not-presupposed information (ErteschikShir 1997). As such, a sentence in canonical order should be felicitous in response to a question which does not presuppose any information (e.g., 'What happened?'), as well as being a felicitous answer to questions which put some or all of the constituents into the discourse context.

This is illustrated with examples from Malayalam below; the new information introduced by the sentence is labeled in brackets $\left(\left[{ }_{F}\right]\right)$ :
a. enta: unta:jite
what.is.it that.happened
b. [ $\quad$ anijan oru pantə erin:u]
Aniyan a ball threw

In (3), all of the information in the sentence is new, so the whole sentences is the focus. In the examples below, what is given is varied, but sov is still a felicitous response to each of these sentences. This demonstrates that each constituent in an SOV sentence can be the focus, a further property of the canonical order in a language: 
(4) $\quad$ Focus $=$ subject
a. ara: panț erijaț who.is.it ball threw.COMP
Who is it that threw the ball?
b. [ ${ }_{F}$ anijan] oru panto erij:u Aniyan a ball threw

(5) $\quad$ Focus $=$ object
a. ența: anijan erinațə what.is.it Aniyan threw.COMP
What is it that Aniyan threw?
b. anijan ${ }_{F}$ oru pantə] erin:u
Aniyan a ball threw

(6) $\quad$ Focus $=$ verb

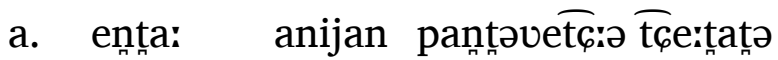 what.is.it Aniyan with.ball did What did Aniyan do with the ball?
b. anijan oru panto [ ${ }_{\mathrm{F}}$ erip:u]
Aniyan a ball threw

(7) $\quad$ Focus $=$ object and verb
a. enta: anijan $\overline{\text { ţ}}$ e:țaț what.is.it Aniyan that.did What is it that Aniyan did?
b. anijan [ ${ }_{\mathrm{F}}$ oru pantə erip:u] Aniyan a ball threw

(8) $\quad$ Focus $=$ subject and object
a. a:rə ento erij:u who what threw Who threw what?
b. [ ${ }_{F}$ anijan oru pantə] erij:u Aniyan a ball threw

(9) Focus $=$ subject and verb
a. enaneja: pantə ivite ețijaț how.is.it ball here reached.COMP How is it that the ball got here?
b. [ ${ }_{\mathrm{F}}$ anijan] pantə ${ }_{\mathrm{F}}$ erij:u] Aniyan ball threw


The answers listed here do not necessarily represent the most likely response to the questions; for example, it is far more likely that speakers would say 'threw' as a response to 'what did Aniyan do with the ball' as opposed to uttering all of the constituents. Because Malayalam allows dropping of all arguments, 'threw' is a well-formed response, but this is also a known property of question-answer pairs. Even in English, which does not generally allow argument-dropping, a very natural response to 'what did Aniyan do with the ball' is 'threw it'. ${ }^{5}$ Regardless, the fact that Sov is a felicitous response to each of these questions means that it passes the diagnostics of being a canonical order in Malayalam. The other orders, being categorized as non-canonical, do not not exhibit these properties. Crucially, this definition allows for the possibility that there could be multiple orders which are canonical; while this not relevant for English or Malayalam, it has been proposed for other languages, so any heuristic to identify canonical order must allow for this possibility.

\subsection{Non-canonical orders and lowered acceptability}

Working from this notion of canonical order, we can consider expectations about the status of non-canonical orders in the context of formal acceptability experiments. Non-canonical constituent orders are usually associated with different syntactic representations than canonical orders are, and, in many syntactic theories, these representations include dependencies analogous to long-distance dependencies, which are well-studied and have been shown to result in reduced acceptability (Cowart 1997) and increased processing difficulty (Kluender \& Kutas 1993). If non-canonical orders indeed contain long-distance dependencies or dependencies which result in a similar behavioral outcome, we would expect similar lowering of acceptability and increased processing difficulty associated with these orders. In fact, psycholinguistic measures have consistently shown that speakers incur some amount of processing difficulty or reduced acceptability associated with non-canonical orders (Kwon et al. (2013) in Korean, Kaiser \& Trueswell (2004) in Finnish, Miyamoto \& Takahashi (2004) in Japanese, Yasunaga et al. (2015) in Kaqchikel Mayan).

Not only are there detectable differences between canonical and noncanonical orders, formal acceptability experiments can detect differences between non-canonical orders. Weskott \& Fanselow (2011) find a relationship between what they call "markedness" and acceptability, with increased

\footnotetext{
${ }^{5}$ This has been analyzed as subject ellipsis by Nariyama (2004), for example.
} 
markedness resulting in decreased relative acceptability. They compare two sets of sentences which differed only in the order of arguments in the embedded clause: SUBJECT-OBJECT versus OBJECT-SUBJECT order and SUBJECT-INDIRECT OBJECT versus INDIRECT OBJECT-SUBJECT order. Example stimuli from their paper are listed in (10) and (11):

(10) Peter has reported that the president has received the sheik.

a. Peter hat erzählt, dass der Präsident den Scheich empfangen Peter has reported that the $\mathrm{NOM}_{\mathrm{NO}}$ president the $_{\mathrm{ACC}}$ sheik received hat

has

CANONICAL ORDER

b. Peter hat erzählt, dass den Scheich der Präsident empfangen

Peter has reported that the $\mathrm{ACC}_{\mathrm{AC}}$ sheik the $\mathrm{N}_{\mathrm{NOM}}$ president received hat

has

NON-CANONICAL ORDER

(11) Peter has reported that the monk has helped the hunter.

a. Peter hat erzählt, dass der Mönch dem Jäger geholfen

Peter has reported that the $\mathrm{N}_{\mathrm{NOM}}$ monk the $\mathrm{DAT}_{\mathrm{DAT}}$ hunter helped hat

has

CANONICAL ORDER

b. Peter hat erzählt, dass dem Jäger der Mönch geholfen

Peter has reported that the $\mathrm{D}_{\mathrm{DAT}}$ hunter the $\mathrm{N}_{\mathrm{NOM}}$ monk received hat

has

NON-CANONICAL ORDER

The (a) sentences have the canonical order of arguments in a German embedded clause, SOV, while the (b) sentences have non-canonical orders, OSV and IOSV. All of these sentences are grammatical, but the non-canonical orders are expected to be less acceptable than the canonical orders. In addition, the INDIRECT OBJECT-SUBJECT order is claimed to be less marked than the OBJECT-SUBJECT order. As such, if acceptability can yield gradient results and distinguish between different grammatical non-canonical orders, the difference in acceptability between the sentences in (10) should be greater than the difference in acceptability between the sentences in (11). 
Participants rated the acceptability of sentences using a 1-7 scale. ${ }^{6}$ On average, the non-canonical orders were always judged to be less acceptable than the canonical orders. In addition, the difference between the canonical and non-canonical orders in (10) was greater than the difference between the canonical and non-canonical orders in (11), showing that acceptability can capture the relative markedness of grammatical constructions. This is the very property which we want in a measure of flexibility in constituent order: a measure which can capture meaningful and potentially subtle differences between grammatical sentences in a language.

So, non-canonical grammatical orders should result in lowered acceptability, and lowered acceptability should correspond to some measure of syntactic or discourse-level complexity. Returning to the intuitive description of flexibility, languages in which orders seem more interchangeable "feel" more flexible than languages in which this is not the case: languages in which more orders are grammatical and relatively acceptable are associated with increased flexibility.

Flexibility is associated with languages which have more grammatical orders, and, via informal methods, those grammatical orders seem to be relatively acceptable. As such, we expect the difference in acceptability between orders to be smaller in flexible languages as opposed to those which have been described as being rigid. Thus, we expect English, a "rigid" language, to have a big difference between canonical and non-canonical orders, and Malayalam, a flexible language, to have a relatively small difference.

It is very likely that the source of lowered acceptability in non-canonical orders (and therefore decreased flexibility) will be different for different languages and, perhaps, different speakers of the same language. This is a feature of this approach. The individual analyst can arrive at their own explanations for why there is lowered acceptability for a given language/variety; this measure is just that, a measure which can be a starting point for a particular analysis. This will be demonstrated further in the following experiments.

6 Their paper compared three different measures of acceptability: 1-7 scales, binary judgments, and magnitude estimation. The pattern of results was similar across methods; I focus on the 1-7 scale because that is the method I used here, and because this method has been shown to be robust in other work, such as Langsford et al. (2018). 


\section{Experiment 1: English constituent order}

Each of the six logical constituent orders falls into one of three categories in English: canonical (sVo), grammatical but non-canonical (OSV), and ungrammatical (sov, vso, vos). As such, English is a good language to serve as a model of how the results of a formal acceptability judgment experiment should correspond with existing descriptions and accounts of constituent order in a language. Under the assumption that non-canonical grammatical orders have the same type of dependency as other types of long-distance dependencies, we expect that non-canonical grammatical orders should result in the same lowering of acceptability as has been observed in a long line of work, starting with Cowart (1997). The examples below show a canonical svo sentence and a topicalized osv sentence in English:

a. I like those trees.

b. $\quad[\text { Those trees }]_{i}\left[\right.$ I like $\left.\emptyset_{i}\right]$

These two sentences differ in that (b) has a dependency and (a) does not. Research on long-distance dependencies in English and non-canonical argument orders in a variety of other languages (Korean, German, Finnish, etc.) has shown consistently that non-canonical constituent orders and/or constructions with syntactic dependencies of this type are less acceptable than their canonical counterparts. So, English sentences in Svo order should be more acceptable than sentences in OSV order. Syntactic dependencies are not the only potential source of lowered acceptability, however. Noncanonical orders are associated with particular discourse functions, and encountering a non-canonical order outside of its proper discourse context should lower acceptability. As such, comparing English Osv with ungrammatical orders like vso and vos is crucial to know whether this measure is fine-grained enough to distinguish between non-canonical orders outside of the proper discourse context and ungrammatical orders in a language.

The distinctions between canonical, non-canonical, and ungrammatical orders in English are salient enough to be observed using informal methods. In order to test whether formal acceptability judgment experiments are properly sensitive as a measure of flexibility, the results must show distinctions between these three sentences types in the predicted direction, with canonical svo having the highest acceptability, followed by non-canonical but grammatical osv, and SOV, Ovs, vso, and vos having the lowest acceptability. 


\subsection{Methods}

\subsubsection{Materials}

Experimental stimuli consisted of animate subjects, inanimate objects, and transitive verbs. Sample stimuli are in Table 2; a full set of stimuli and recordings can be found in the supplementary materials. Both arguments had indefinite articles; this was chosen for consistency across conditions, in order to avoid a potential confound of definiteness and order. 30 lexicalization sets were created, and items were counterbalanced and distributed among six lists using a Latin Square. Participants heard five items from each of the six conditions (SOV, OSV, SVO, OVS, VSO, VOS), for a total of 30 experimental items. There were 56 fillers of varying acceptability, 24 of which were part of a sub-experiment on D-linking. Stimuli were recorded in a soundproof booth by a young woman speaker of American English. For grammatical sentences, the speaker used natural intonation, and took care to produce a similar intonational contour within conditions. For ungrammatical sentences, the speaker invented a particular intonational contour which sounded as natural as possible, and, again, took care to produce the same contour for each sentence which had a similar structure.

Table 2: Experiment 1 sample stimuli.

\begin{tabular}{|c|l|}
\hline CONDITION & SAMPLE STIMULUS \\
\hline \hline SOV & A magician a safe locked. \\
\hline OSV & A safe a magician locked. \\
\hline SVO & A magician locked a safe. \\
\hline OVS & A safe locked a magician. \\
\hline VSO & Locked a magician a safe. \\
\hline VOS & Locked a safe a magician. \\
\hline
\end{tabular}

The sentences above fall into three distinct categories: canonical (svo), grammatical but non-canonical (OSv), and ungrammatical (SOV, OVs, Vso, and vos). Based solely on this, canonical svo should be most acceptable, followed by Osv, the grammatical but non-canonical order. The ungrammatical orders should have relatively low acceptability, though osv order, like in a sentence a safe locked a magician, could be interpreted by participants as an implausible svo sentence, perhaps describing an event in which an anthropomorphic safe is locking up a magician. As such, the ovs sentences could potentially be rated relatively high, like the svo sentences, or relatively low, like the ungrammatical orders. 


\subsubsection{Participants and procedure}

133 individuals participated in this experiment in 2019. The experiment was distributed on Prolific.ac, an online platform for recruiting research participants. Only participants whose location was in the United States (determined via IP address) were analyzed in this study, which brought the total number of participants analyzed to 80 . In order that the participants would be of a similar age to those in Experiment 2, only participants between 18 and 30 were recruited. Participants were paid \$3.50 each, and the experiment took 12 minutes to complete on average.

The experimental materials were presented in Qualtrics. Participants were instructed that they would hear English sentences and then be asked to rate how good those sentences sound. They were asked to give their first reaction, and note that there are no correct answers. They were also asked to make sure that they were in a quiet place or that they had good headphones. At the end of the experiment, participants completed a brief demographic and language background questionnaire.

Table 3 summarizes the predictions for Experiment 1.

Table 3: Experiment 1 predictions.

\begin{tabular}{|c|l|c|}
\hline CONDITION & SAMPLE STIMULUS & RELATIVE ACCEPTABILITY \\
\hline \hline SOV & A magician a safe locked. & low \\
\hline OSV & A safe a magician locked. & second-highest \\
\hline SVO & A magician locked a safe. & highest \\
\hline OVS & A safe locked a magician. & unclear \\
\hline VSO & Locked a magician a safe. & low \\
\hline VOS & Locked a safe a magician. & low \\
\hline
\end{tabular}

\subsection{Results}

Responses were transformed into by-subject z-scores to account for individual variation in how the scale was used. ${ }^{7}$ Results are plotted as density plots in (1). The mean is represented by a dotted line, and the individual responses are represented by the hashes above the $\mathrm{x}$-axis.

Canonical svo order had the highest acceptability (mean rating $=5.93$; mean z-score $=0.91$ ), followed by non-canonical osv (mean rating $=4.08$;

7 Z-scores were calculated using all of the ratings given by a participant, including fillers. 


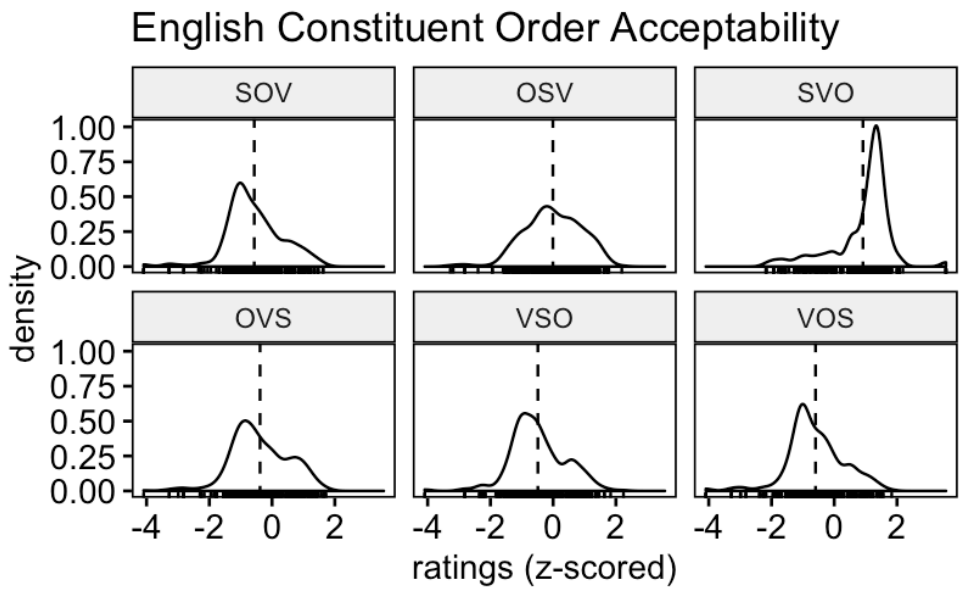

Figure 1: Density plot of the z-scored acceptability ratings. The dashed line represents the mean z-scored rating.

mean z-score $=-0.01$ ). Because svo is the canonical order, I re-leveled the data in relation to SVO and fitted a linear mixed-effects model using the lme4 package in $\mathrm{R}$ (Bates et al. 2015) (fixed effects = CONDITION and RESPONSE; random effects = PARTICIPANT and LIST). The coefficients of that model are plotted in (2). The question of statistical significance between orders is not a crucial part of the approach presented here; it suffices to show that the canonical order is rated higher than the non-canonical order, and that the remaining orders are rated lower.

\subsection{Discussion}

The formal acceptability judgment experiment presented here distinguished between canonical, non-canonical, and ungrammatical constituent orders. As expected, canonical svo order was most acceptable, and the ungrammatical orders were least acceptable. There was a significant difference between sVo order and the non-canonical OSV order, corresponding to the observation that English is an svo language.

The acceptability task yielded results which were fine-grained enough to show that speakers treated ovs order differently from topicalized OSV constructions and the clearly ungrammatical sov, vso, and vos orders. In one sense, this is too much information - the goal is to distinguish between canonical, non-canonical, and ungrammatical orders - but the difference 


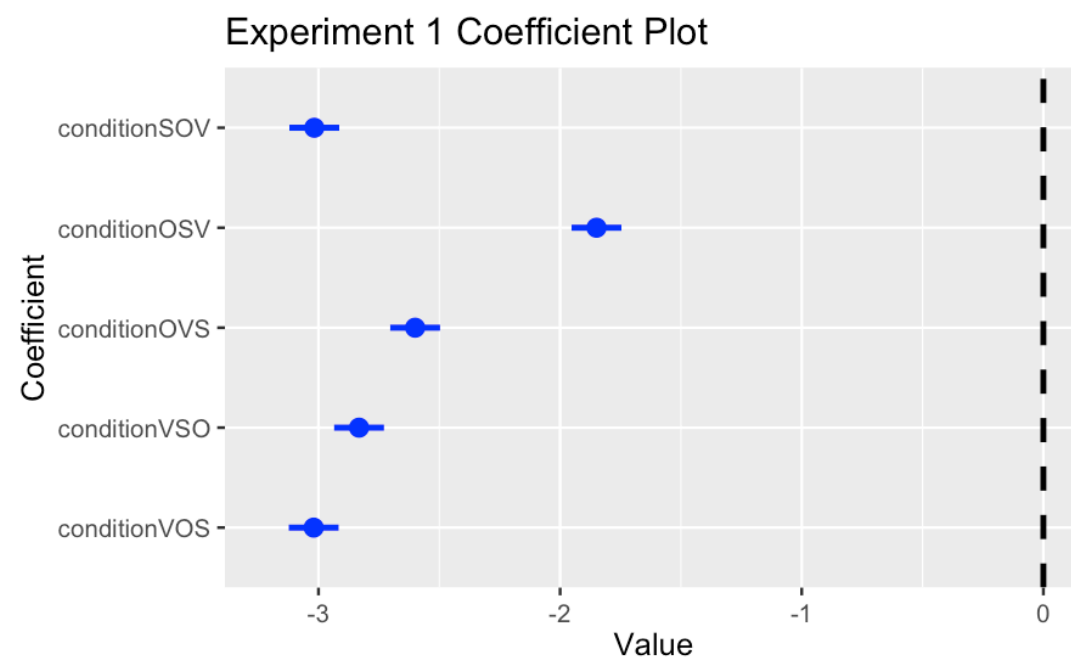

Figure 2: Coefficient plot for Experiment 1. Fixed effects $=$ cONDITION \& RESPONSE; random intercepts = LIST \& PARTICIPANT. Fixed effects were coded against svo, the mean acceptability of which is represented by the dotted line. Dots represent model coefficients for each condition, and the bars represent $95 \%$ confidence intervals. 
between ovs and the ungrammatical orders is small, and the results are interpretable given some basic assumptions about how speakers are reacting to sentences like The safe locked the magician. In future versions of this experiment, constructing a context in which the intended propositional content is held constant in order to ensure that participants interpret the sentences in a more uniform way would address this possibility. However, the fact that the intonational contour for ovs orders was systematically different from that of svo orders does reduce the likelihood that speakers are considering this to be an implausible svo sentence.

Thinking about discourse context, it is an empirical question whether non-canonical OSV order might increase in acceptability if embedded in the proper discourse context; research in other languages indicates that this is highly likely. Because the degree to which non-canonical orders are tied to a particular discourse context is variable across languages (Fortescue 1993), a parallel set of studies investigating the role of discourse context would be an important avenue of future research to supplement these results.

In sum, Experiment 1 shows that formal acceptability experiments can yield meaningful results in a well-studied language like English, for which the facts about constituent order are relatively agreed upon (e.g., Birner \& Ward 1998). In order to test whether this approach can capture crosslinguistic differences, yielding bigger differences between canonical and non-canonical orders in languages which are more rigid and smaller differences in languages which are more flexible, we turn to Experiment 2: Malayalam constituent order.

\section{Experiment 2: Malayalam constituent order}

As discussed in Section 2, all six logical orderings of SUBJECT, OBJECT, and VERB are grammatical and have the same truth-conditional meaning in Malayalam. However, we do not expect these six orders to have the same status in the language, and, as a consequence, we do not expect them to be equally acceptable. Following the work discussed in Section 2, canonical sov order should have the highest acceptability. I appealed to the existence of a syntactic dependency in order to motivate lower acceptability for topicalized OSV order in English; as OSV order has also been analyzed as containing a syntactic dependency in Malayalam (Jayaseelan 2008), OSV should be less acceptable than canonical sov:

a. li:la oru pustakam va:jiţ $\bar{u}$
Leela a book read 


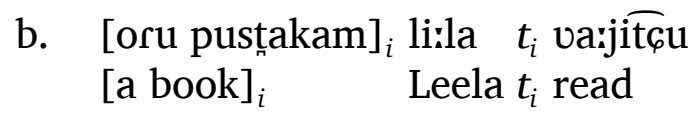

In (13b), the object is in brackets to highlight that the whole phrase oru pustakam 'a book' participates in this dependency.

However, syntactic accounts of the verb-medial and verb-initial orders in Malayalam are underdescribed at best, and, in fact, these orders are not often included in theoretical accounts. The most well-known reference grammar for Malayalam (Asher \& Kumari 1997) does not describe any non-verbfinal orders. This is not unique to Malayalam: canonically verb-final languages like Korean, Turkish, and Tamil (all of which are better-studied than Malayalam) allow non-verb-final orders, but this property is not typically described outside of work looking specifically at these constructions. This is unsurprising given the peripheral nature of these sentence-types, and it is partly a consequence of flexibility not being studied in its own right. The following section goes over previous accounts of constituent order in Malayalam and proposes an account which could motivate particular differences in acceptability between non-canonical grammatical orders in Malayalam (which, potentially, can be extended to other syntactically similar languages as well).

\subsection{Dependencies as a source of lowered acceptability in verb- medial and verb-initial sentences}

Although non-canonical orders in Malayalam are relatively under-described, ${ }^{8}$ the language played a role in previous debates about (non-)configurationality. Mohanan (1982) argued that Malayalam has a flat VP structure; on his analysis, each order results from the same operation, and a verb's arguments have a symmetrical relation to each other on the level of constituent structure. ${ }^{9}$ This account does not make predictions based on differences in syntactic movement about how acceptable the different orders should be relative to each other, as each order is generated through the same operation. ${ }^{10}$ From a different perspective, Jayaseelan (2008) does not account

8 Though see Leela (2016) for a study of the acquisition of a subset of the non-canonical orders in Malayalam

${ }^{9}$ Mohanan worked within Lexical-Functional Grammar (LFG), in which the constituent structure of a sentence (word order) and its semantic structure (valency of arguments) need not be directly mapped onto one another.

${ }^{10}$ Non-movement accounts of constituent order are not limited to a particular theoretical approach; a relatively recent example comes from Fanselow (2003), who works within the 
for non-verb-final orders in his analysis, but argues that the different constituent orders result from argument movement into SPEC focus and SPEC topic positions, derived from a basic sov order; this allows Malayalam to fit into frameworks which require argument structure to be configurationally represented in the syntactic structure. On this analysis, Sov is the underlying order and each deviation from this order requires either topicalization or focus movement. Assuming this type of syntactic movement also assumes that a dependency is created between the moved constituent and its trace in the original position.

These two approaches differ mainly in terms of the level of analysis at which non-canonical orders differ from canonical orders. In an LFG account, ${ }^{11}$ the dependency is between the argument and the verb, while in an account like Jayaseelan's, the dependency is between the argument and its trace. As discussed by Sag \& Fodor (1994), psycholinguistic results are compatible with both conceptions of 'dependency,' and, as such, I follow the convention of psycholinguists who use the word dependency in a way that is neutral to these alternatives. Sentences with displaced arguments do result in processing difficulty and lowering of acceptability, no matter the level of analysis at which this dependency resides. Conceiving of the difference between canonical and non-canonical orders as resulting from dependencies in this psycholinguistic sense is additionally advantageous because, as discussed in Section 2, the lowering in acceptability associated with non-canonical orders is similar to the lowering in acceptability associated with long-distance dependencies, which have been more-thoroughly investigated.

I propose that verb-position should correspond to acceptability in Malayalam constituent order, with verb-final orders being more acceptable than verb-medial orders, which should be more acceptable than verb-initial orders. Previous studies have shown that readers posit a canonical order in languages like German, Korean, Finnish, Japanese and Hindi (Miyamoto \& Takahashi 2001; Vasishth 2002), and speakers have expectations about the order of constituents, that, when violated, lead to increased processing effort and reduced acceptability. I sketch an account of what Malayalam speakers' expectations about constituent order might be, given that Malay-

Minimalist framework. He argues, using evidence from German, that sentences in noncanonical order need not involve movement unless there is evidence for movement from other domains of the grammar like prosody, so non-canonical orders can also be basegenerated.

11 This also applies to versions of Head-Driven Phrase Structure Grammar or HPSG which do not include traces of movement as syntactic objects (e.g., Sag \& Fodor 1994) 
alam is canonically verb-final, allows argument dropping, and all six orders are grammatical. Namely, I expect that Malayalam speakers experience processing difficulty associated with the dependencies created by post-verbal arguments and rate them as less acceptable.

Consider the experience of Malayalam speakers (14a) and English speakers (14b) as they hear a sentence which is communicating the following event:

$$
\begin{aligned}
& \text { BOUGHT<Ammu, hat〉 } \\
& \text { a. Ammu oru top:i va:ni } \\
& \text { Ammu a hat bought } \\
& \text { b. Ammu bought a hat }
\end{aligned}
$$

In both cases, the major constituents are in canonical order. When English speakers hear a subject and a transitive verb, as in (14b), they expect an object to follow. When Malayalam speakers hear the verb in a sentence like (14a), they have already heard a subject and an object, and they have a strong expectation that no additional arguments will follow the verb; the verb signals the end of the sentence. Malayalam also allows argumentdropping: while English speakers find (15a) ungrammatical, even in the context of (15), Malayalam speakers do not find (15b) to be ungrammatical or very unacceptable. In fact, subjects and objects both can be dropped, as in $(15 \mathrm{c}):^{12}$

(15) Where did that hat come from?
a. * Ammu bought
b. Ammu va:ni
Ammu bought
c. va:yi
bought

This means that Malayalam speakers hearing a subject followed by a transitive verb have reason to expect that they are hearing a sentence with a null argument, as in (16), where $\emptyset$ represents the canonical position of the null object:

$$
\begin{aligned}
& \text { Ammu } \emptyset \text { va:ni } \\
& \text { Ammu } \emptyset \text { bought }
\end{aligned}
$$

\footnotetext{
12 The default interpretation is that the speaker is the subject of the sentence, unless Ammu
} was otherwise salient in the discourse or the speaker was ruled out in some way. 
As such, when an object follows the verb, as in (17), we expect that speakers incur some processing cost, as they must associate the null argument with the overt argument:

$$
\begin{aligned}
& \text { Ammu } \left.\emptyset_{i} \text { va:ni [oru top:i }\right]_{i} \\
& \text { Ammu } \emptyset_{i} \text { bought }\left[\begin{array}{ll}
\text { a } & \text { hat }
\end{array}\right]_{i}
\end{aligned}
$$

This analysis is fully compatible with frameworks which differ as to whether they assume a syntactic object associated with the position of the null argument, as well as syntactic analyses which differ as to whether the $\emptyset$ represents a null pronoun or the trace of syntactic movement. In frameworks which do assume that the null argument has an associated syntactic object, this relationship can be stated as a cost associated with syntactic movement or the creation of the dependency between these two elements. In frameworks which do not assume there is syntactic material in this position, this can be stated as a difficulty associated with reanalysis of argument structure/theta role reassignment (as in LFG or HPSG), or cost associated with selecting a less activated or expected syntactic structure. ${ }^{13}$ As such, even though the sentence in (17) is grammatical, there is an expectation that the presence of a post-verbal argument will lead to reduced acceptability.

The same logic applies to a sentence in ovs order:

$$
\begin{aligned}
& \emptyset_{i} \text { oru top:i va:yi }[\mathrm{Ammu}]_{i} \\
& \emptyset_{i} \text { a hat bought }[\mathrm{Ammu}]_{i}
\end{aligned}
$$

In both of the verb-medial cases, there is processing cost associated with a single argument appearing in a non-canonical post-verbal position, which, as with OSV order, should correspond to reduced acceptability. For verbinitial orders, two arguments appear in non-canonical positions:

$$
\begin{aligned}
& \emptyset_{i} \emptyset_{j} \text { va:ni }[\mathrm{Ammu}]_{i}[\text { oru top:i }]_{j} \\
& \emptyset_{i} \emptyset_{j} \text { bought }[\mathrm{Ammu}]_{i}[\mathrm{a} \text { hat }]_{j} \\
& \left.\emptyset_{i} \emptyset_{j} \text { va:ni [oru top:i }\right]_{j}[\mathrm{Ammu}]_{i} \\
& \left.\emptyset_{i} \emptyset_{j} \text { bought [a hat }\right]_{j}[\mathrm{Ammu}]_{i}
\end{aligned}
$$

The fact that there are two arguments in non-canonical positions - and therefore two associations which speakers must make - leads to the ex-

13 I assume only that there is some difficulty associated with the non-canonical position, as the sentence types tested here do not distinguish between these accounts. 
pectation that this should result in even lower acceptability for verb-initial sentences as compared with verb-medial sentences.

\subsection{Analyses for all constituent orders}

(21) summarizes the analyses for all orders in Malayalam:

$$
\begin{aligned}
& \text { BOUGHT〈Ammu, hat) } \\
& \text { a. Ammu oru top:i va:ji } \\
& \text { Ammu a hat bought } \\
& \text { sov canonical } \\
& \text { b. [oru top:i }]_{i} \text { Ammu } t_{i} \text { va:yi } \\
& \text { [a hat }]_{i} \text { Ammu } t_{i} \text { bought } \\
& \text { OSV } \\
& \text { c. Ammu } \left.\emptyset_{i} \text { va:ni [oru top:i }\right]_{i} \\
& \text { Ammu } \left.\emptyset_{i} \text { bought [a hat }\right]_{i} \\
& \text { SVO } \\
& \text { d. } \emptyset_{i} \text { oru top:i va:ni }[\mathrm{Ammu}]_{i} \\
& \emptyset_{i} \text { a hat bought }[\mathrm{Ammu}]_{i} \\
& \text { ovs } \\
& \text { e. } \emptyset_{i} \emptyset_{j} \text { va:ni } \quad[\mathrm{Ammu}]_{i}[\text { [oru top:i }]_{j} \\
& \emptyset_{i} \emptyset_{j} \text { bought }\left[\mathrm{Ammu}_{i}\left[\begin{array}{ll}
\mathrm{a} & \text { hat }
\end{array}\right]_{j}\right. \\
& \text { VSO } \\
& \text { f. } \emptyset_{i} \emptyset_{j} \text { va:ni } \quad[0 r u \text { top:i }]_{j}[\mathrm{Ammu}]_{i}
\end{aligned}
$$

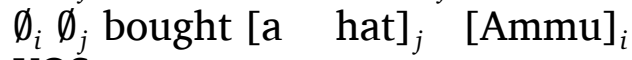

$$
\begin{aligned}
& \text { vos }
\end{aligned}
$$

It could be that OSV is different from the other non-canonical orders, as the other non-canonical orders involve dependencies which occur across the verb. From an incremental parsing perspective, hearers have heard all of the arguments by the time they hear the verb in Osv sentences. However, in verb-medial and verb-initial sentences, this is not the case: when hearers encounter the verb in an svo sentence for example, they would be reasonable to assume the sentence is over, since argument-dropping is an option. As such, they have already posited one or two null arguments which must be accounted for when they hear post-verbal arguments. So, canonical order should be most acceptable, followed by Osv, the verb-medial orders (in which hearers have to account for one post-verbal argument), and finally, the verb-initial orders (in which hearers have to account for 
two post-verbal arguments). ${ }^{14}$ This account is appealing because it makes clear predictions which are motivated by relatively basic assumptions. In addition, it makes the prediction that other canonically verb-final argumentdropping languages, like Japanese and Korean, should show the same pattern of acceptability that Malayalam does.

\subsection{Methods}

\subsubsection{Materials}

Experimental stimuli consisted of animate subjects, inanimate objects, and transitive verbs, as shown in Table 4. As a reminder, subjects and inanimate

Table 4: Experiment 2 sample stimuli.

\begin{tabular}{|c|c|}
\hline CONDITION & SAMPLE STIMULUS \\
\hline SOV & $\begin{array}{l}\text { tipku oru ma:ya tiñu } \\
\text { Tinku a mango ate }\end{array}$ \\
\hline OSV & $\begin{array}{l}\text { oru ma:ya tinku tiñu } \\
\text { a mango Tinku ate }\end{array}$ \\
\hline SVO & $\begin{array}{l}\text { tipku tin:u oru ma:ya } \\
\text { Tinku ate a mango }\end{array}$ \\
\hline OVS & $\begin{array}{l}\text { oru ma:ya tin:u tipku } \\
\text { a mango ate Tinku }\end{array}$ \\
\hline VSO & $\begin{array}{l}\text { tinn:u tinku oru ma:ya } \\
\text { ate Tinku a mango }\end{array}$ \\
\hline VOS & $\begin{array}{l}\text { tiñ }: u \text { oru ma:na tipku } \\
\text { ate a mango Tinku }\end{array}$ \\
\hline
\end{tabular}

objects are not overtly marked for case, so none of these sentences have overt case-marking. In addition, verbs do not agree with subjects or objects. However, because the subjects are animate and objects are inanimate, these sentences are not ambiguous as to who did what to whom. Subjects and objects were bisyllabic in order to avoid possible effects of heavy NP-shift, though objects were preceded with the indefinite article oru.

30 lexicalization sets were constructed, and items were distributed across 6 lists using a Latin Square. Audio stimuli were recorded in a soundproof

14 It could be that the dependency associated with a post-verbal object is easier than the dependency associated with a post-verbal subject, for example, but the account outlined here does not make a prediction either way. 
booth by a young woman speaker of Malayalam. The appropriate intonation associated with each order was used in order to avoid the possibility that participants would find non-canonical orders to be less acceptable because of this. Care was taken to ensure uniformity within conditions by spot-checking intonational contours in Praat. Each participant heard 5 tokens from each of the 6 conditions. There were 40 filler sentences; 30 of these constituted a sub-experiment about adjunct island extraction and were bi-clausal sentences, and the remaining 10 were ungrammatical fillers of varying lengths. ${ }^{15} \mathrm{~A}$ total of 70 sentences, 30 of which were experimental items, were heard by each participant.

\subsubsection{Participants and procedure}

The participants in this experiment were 18 Malayalam-speaking MA and $\mathrm{PhD}$ students in Statistics at University of Cochin in central Kerala, India, which is where Malayalam is spoken. Though their education level is higher than the general population in Kerala, the language backgrounds of these participants are not unusual (as confirmed in Kerala Department of Education (2011), a report of educational census data from the Kerala Department of Education).

Participants were told to keep in mind everyday conversational Malayalam (as opposed to the written form of the language) and rate each sentence based on how natural it sounded, keeping in mind that some sentences would sound normal and others would be non-sentences. The experiment was run on a laptop using a built-in rating program MFCExperiment in Praat (Boersma \& Weenink 2013). Stimuli were presented through headphones, with the 1-7 scale on the screen. Participants could enter their respond by clicking on the numbers using the laptop's trackpad or using the number keys. After the response was entered, the next sentence played with a 500 millisecond gap between the participant's response and the next sentence. Each sentence could only be heard once. After completing the experiment, a 10 minute language background interview was conducted orally with each participant. The screen participants saw when they were asked to provide a rating is shown in Figure 3.

15 The fillers had transitivity violations and/or errors in case-marking. 


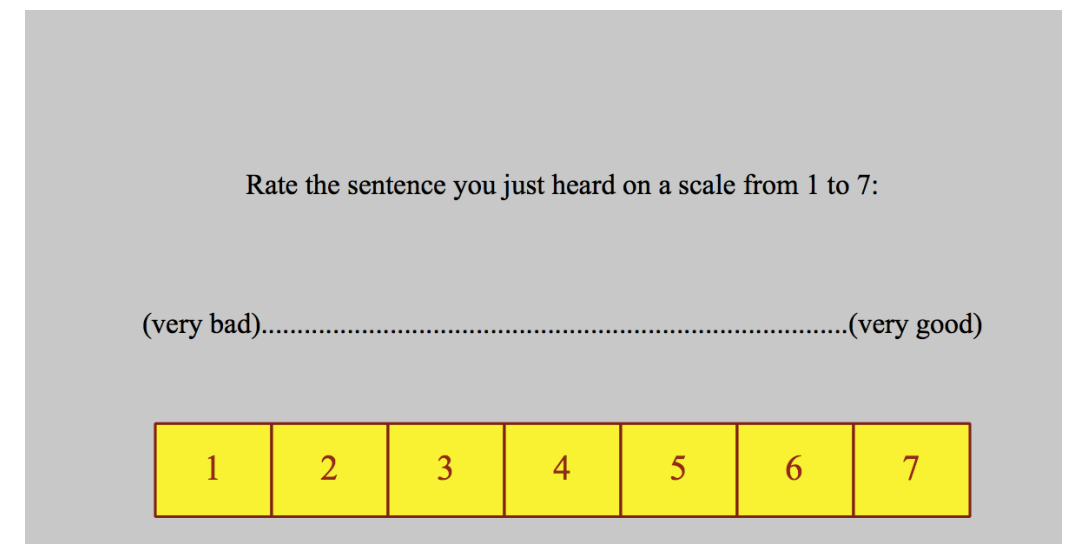

Figure 3: Image of the screen seen by participants in Experiment 2.

\subsection{Predictions}

Unlike in English, the experimental stimuli are all grammatical in Malayalam. We expect at minimum that canonical sov order should be more acceptable than the other orders. Based on the account discussed in 4.2, we further expect that verb-medial orders should have lower acceptability than verb-final orders, and verb-initial orders should have the lowest acceptability of all. We also expect that the difference between canonical sov order and non-canonical orders in Malayalam should be smaller than the difference between canonical svo order in English and non-canonical osv, as this is our indicator of reduced reliance on canonical order. These predictions are summarized in Table 5.

\subsection{Results}

Responses were transformed into by-subject z-scores in order to account for individual variation in how the scale was used, and the results are plotted in Figure 4. The verb-final orders SOV and OSV had the highest acceptability (mean rating $=5.40$ and mean z-score $=1.05$ for sov; mean rating $=4.94$ and mean z-score $=0.80$ for OSV), followed by the verb-medial orders SVO and ovs. The verb-initial orders vos and vso had the lowest acceptability.

Because SOV is the canonical order in Malayalam, I re-leveled the data in relation to SOV and fitted a linear mixed-effects model using the lme4 package in $\mathrm{R}$ (Bates et al. 2015) (fixed effects = CONDITION and RESPONSE; 
Table 5: Experiment 2 predictions.

\begin{tabular}{|c|l|c|}
\hline CONDITION & SAMPLE STIMULUS & RELATIVE ACCEPTABILITY \\
\hline \hline SOV & $\begin{array}{l}\text { tijku oru ma:ya tin:u } \\
\text { Tinku a mango ate }\end{array}$ & highest \\
\hline OSV & $\begin{array}{l}\text { oru ma:ya tijku tin:u } \\
\text { a mango Tinku ate }\end{array}$ & second-highest \\
\hline SVO & $\begin{array}{l}\text { tijku tin:u oru ma:ya } \\
\text { Tinku ate a mango }\end{array}$ & third-highest \\
\hline OVS & $\begin{array}{l}\text { oru ma:ya tinn:u tinku } \\
\text { a mango ate Tinku }\end{array}$ & third-highest \\
\hline VSO & $\begin{array}{l}\text { tin:u tinku oru ma:ya } \\
\text { ate Tinku a mango }\end{array}$ & lowest \\
\hline VOS & $\begin{array}{l}\text { tin:u oru ma:ya tinku } \\
\text { ate a mango Tinku }\end{array}$ & lowest \\
\hline
\end{tabular}

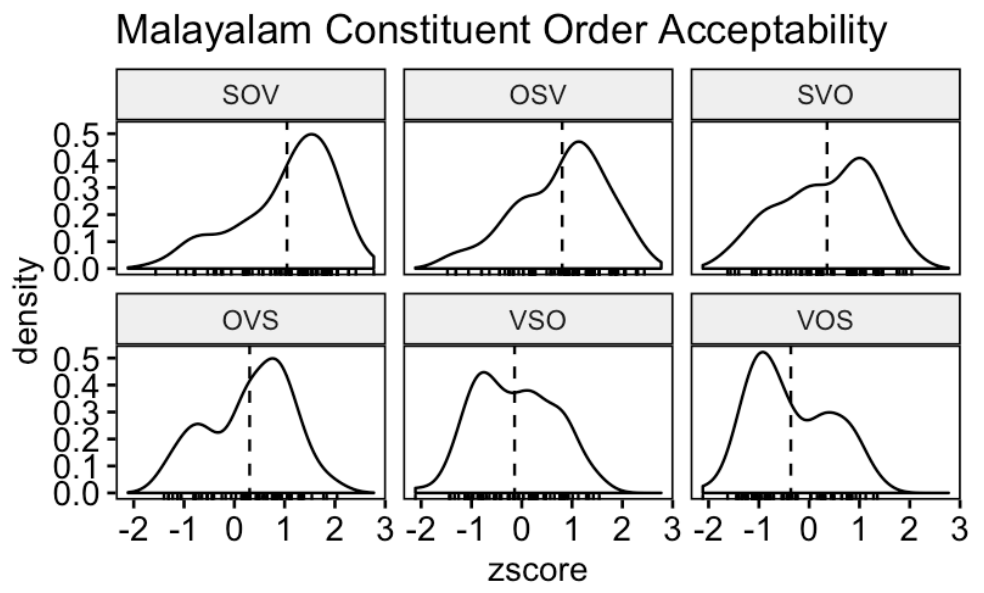

Figure 4: Density plot of the z-scored acceptability ratings. The dashed line represents the mean $z$-scored rating. 


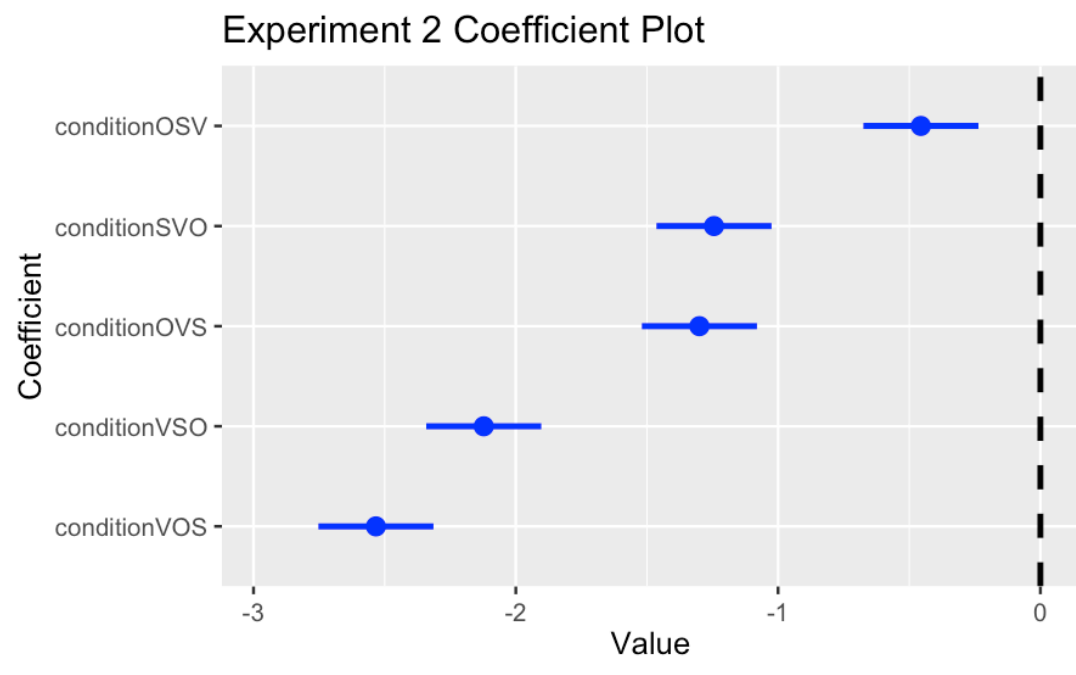

Figure 5: Coefficient plot for Experiment 2. Fixed effects = CONDITION \& RESPONSE; random intercepts = LIST \& PARTICIPANT. Fixed effects were coded against Sov, the mean acceptability of which is represented by the dotted line. Dots represent model coefficients for each condition, and the bars represent $95 \%$ confidence intervals.

random effects $=$ PARTICIPANT and LIST). The coefficients of that model are plotted in (5).

\subsection{Discussion}

This experiment was a first step toward a full profile of Malayalam constituent order profile which includes all six grammatical orders. Overall, the results align with the predictions made in Table 5 . There is a relatively small difference between SOV and OSV orders - small enough in fact that the difference was not statistically significant using a post-hoc t-test. This could be explained if the dependency created by fronting the object in the OSV sentences was not "difficult" enough to show a reduction of acceptability; there was only one word in between the object and its canonical position. Replicating this study with longer arguments would likely yield a perceptible difference in acceptability between these two verb-final orders. ${ }^{16}$ The account in Section 4.2 did not predict differences between svo

16 The experiment in Namboodiripad (2017), Chapter 4, does find a difference between sov and other non-canonical orders in Malayalam, at least for some participants. 
and ovs orders, nor vso and vos orders, and the results here also did not find a difference between these orders. This does not rule out the possibility that these differences might be present at some other level of analysis, or with longer or more complex arguments. Regardless, this methodology detected meaningful differences between non-canonical orders, and between canonical and non-canonical verb positions.

There is some previous research which supports the pattern found here. While large, balanced corpora of spoken Malayalam do not currently exist, Leela (2016) constructed and analyzed a database of casual Malayalam from online sources. Her database consisted of 5598 declarative sentences (excluding clefts, passives, and ditransitive sentences), and the frequencies in that study align with the acceptability results in Experiment 2: sov order was the most frequent order, representing $21.4 \%$ of all sentences, followed by OSV $(17.6 \%)$, then the verb-medial orders (svo $=12.2 \%$ and ovs $=$ $13.9 \%$ of sentences). She did not find any verb-initial orders with all three constituents, ${ }^{17}$ but verb-initial vo and vs orders represented 6.2 and 8.9 percent of the sentences respectively. While SOV is the most frequent order in this database, it represents just one-fifth of all declarative transitive sentences and is not twice as frequent as the next more frequent order. ${ }^{18}$ The convergent results from these two studies is reassuring that these findings are not solely task-specific, though converging evidence via other methods would be ideal.

\section{Relative acceptability as a measure of flexibility}

This paper argues that flexibility should be studied in its own right as a dimension along which languages vary, and it proposes a novel application of formal acceptability judgment experiments - as a cross-linguistically valid measure of flexibility in constituent order. The two experiments show that this method can capture differences between languages that have been described to differ in flexibility, English and Malayalam, which differed in the predicted direction: English, which is less flexible than Malayalam, showed a bigger difference in acceptability between canonical and non-canonical orders than did Malayalam. The results from both experiments are plotted side-by-side in Figure 6. All six logical orders for each language are plot-

${ }_{17}$ It is worth noting that $33 \%$ of the 5598 sentences had one or more null arguments.

18 This would place Malayalam in the category "No Dominant Order" under Dryer's standards in WALS. 
ted; I call this the CONSTITUENT ORDER PROFILE for each language, as it provides a picture of the relative status of each order.

While the differences in the constituent order profiles of these two languages are visually striking, this methodology must be systematically replicated in order to construct a taxonomy of flexibility in constituent order. Replications of this method with Korean (Namboodiripad et al. 2019) and Avar (Zaslansky \& Namboodiripad 2019) have shown that it is useful beyond English and Malayalam, and the potential for cross-linguistic comparison means that psycholinguistic methods such as formal acceptability experiments can be used to investigate syntactic typology. Experiments can be helpful (or crucial) to account for subtle syntactic phenomena such as flexible constituent order. Informal elicitation can be very challenging in this empirical domain; if the differences between non-canonical grammatical orders are relatively subtle, distinguishing between these orders via introspection is by definition difficult. ${ }^{19}$

Experimental methods can also supplement insights gained from studies of non-canonical orders which rely on corpora (such as Gregory \& Michaelis (2001)). The relationship between corpus frequencies and flexibility requires further inquiry, as the contexts in which a construction appears might be infrequent, though the construction itself could be relatively acceptable. As observed in Quakenbush (1992), the most frequent order can vary based on the genre; in Agutaynon, verb-initial patterns are most common in narrative, SV order in non-narrative. In addition, the relationship between frequency and acceptability is not necessarily bidirectional: while frequent constructions are often relatively high in acceptability, and constructions which are low in acceptability are often relatively infrequent, highly acceptable constructions can be very infrequent (Bermel \& Knittl 2012). Finally, even for languages like Malayalam, which has a writing system and a long and extensive literary culture, diglossia is an issue; non-verb-final orders seem to be more of a spoken language phenomenon, which is why Leela (2016) had to construct her own database to study these constructions.

Taking a gradient approach to constituent order flexibility has implications for explanatory accounts in typology. For example, argument-marking, whether via flagging on arguments or indexing on/near verbs, has been cited facilitating or allowing flexibility (Fedzechkina et al. 2017). While

19 Thomason (2003) provides an instantiation of this in her discussion of Salish and Kadiwéu, both of which are languages in which each of the six logical orders is grammatical. The elicitation language was less flexible in each case (English and Portuguese, respectively), which led to initial misdescriptions because the order of the elicitation language was overrepresented due to it being grammatical (though non-canonical). 


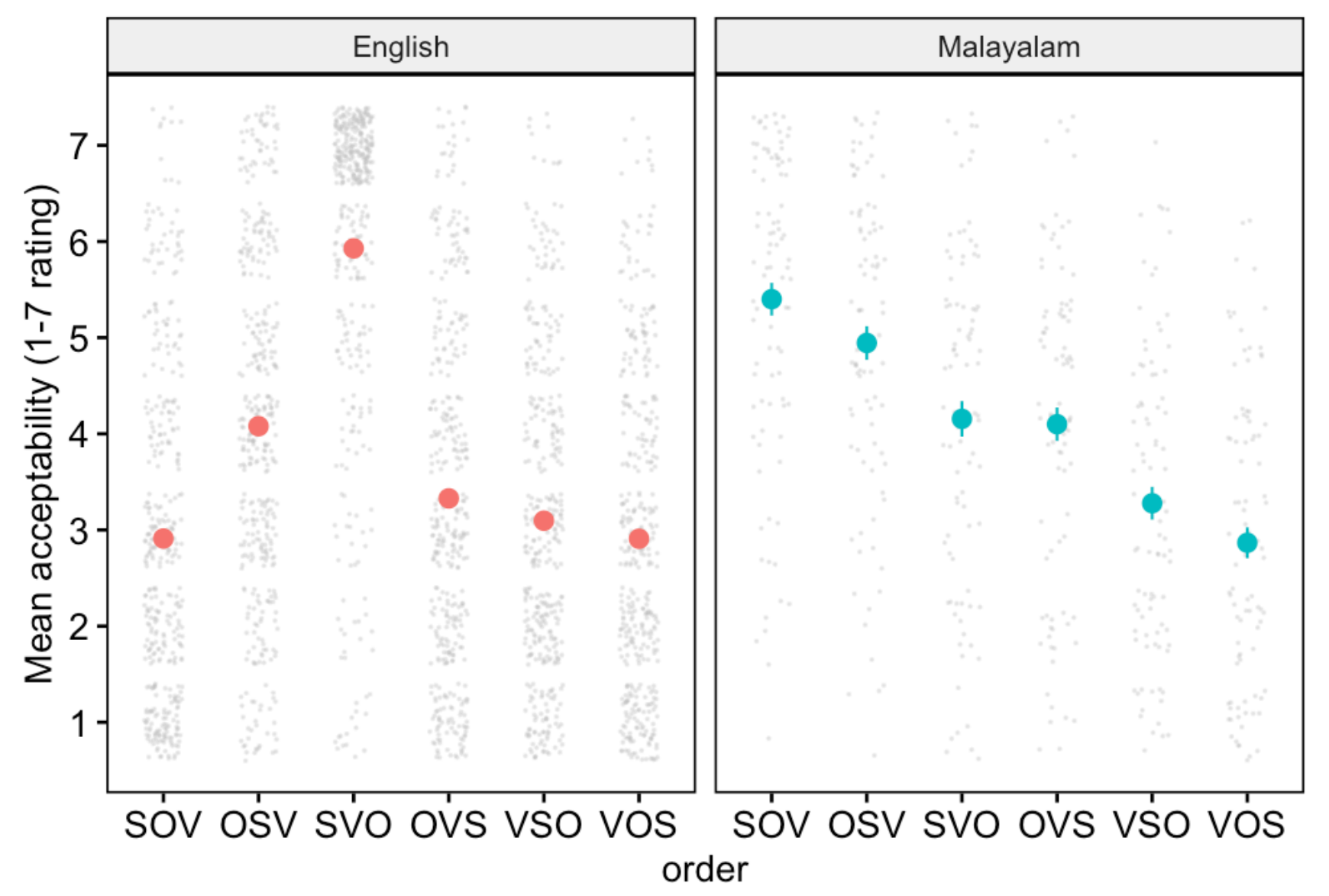

Figure 6: Constituent Order Profiles of English (Experiment 1) and Malayalam (Experiment 2). Mean 1-7 ratings for each order are plotted, and the bars represent standard error. Each transparent gray dot represents a single rating. 
there is certainly some type of relationship between argument-marking and flexibility, one does not entail the other, as demonstrated by the counterexamples to the relationship between overt argument-marking and flexibility: Icelandic has case-marking but rigid order (Kiparsky 1996) and Lao is a "radically isolating language" which allows for flexible order (Enfield (2009), also Gil (2005) for Riau Indonesian). A gradient notion of flexibility opens the door for careful testing of hypotheses about the relationship between flexible constituent order and other empirical domains such as argument marking.

Finally, the title of this paper is very intentionally "A gradient approach to flexible constituent order," and not "Constituent order flexibility is gradient." It very well could be that languages do differ categorically, and that they will cluster into groups corresponding to "positional" and "morphological", or they could cluster based on how many orders are grammatical, or by contact history, and so on. Assuming differences in degree and not kind should be the null hypothesis in studies of cross-linguistic variation, and, I argue, by allowing for but not entailing categorical variation, the method presented here can enrich typological inquiries.

\section{Abbreviations (mandatory)}

$\mathrm{S}=$ subject, $\mathrm{O}=$ object, $\mathrm{V}=$ verb, COMP $=$ complementizer, $\mathrm{NOM}=$ nominative, ACC $=$ accusative, SPEC $=$ specifier

\section{Supplementary files (optional)}

The full set of stimuli used in the experiments, data, and associated $\mathrm{R}$ code can be found at the following URL: To appear in de-anonymized version.

\section{Ethics and consent (optional)}

To appear in de-anonymized version.

\section{Funding information (optional)}

To appear in de-anonymized version. 


\section{Acknowledgements (optional)}

To appear in de-anonymized version.

\section{Competing interests}

The author has no competing interests to declare.

\section{References}

Aikhenvald, Alexandra Y. 2003. Mechanisms of change in areal diffusion: new morphology and language contact. Journal of Linguistics 39(1). 1-29. http://dx.doi.org/10.1017/S0022226702001937. http: //www.journals.cambridge.org/abstract_S0022226702001937.

Asher, R E \& T C Kumari. 1997. Malayalam (Descriptive Grammars Series). Kluwer Academic Publishers.

Austin, Peter \& Joan Bresnan. 1996. Non-configurationality in australian aboriginal languages. Natural Language \& Linguistic Theory 14(2). 215268.

Bailyn, John F. 2012. The syntax of russian. Cambridge University Press.

Barbiers, Sjef. 2000. The right periphery in sov languages. The Derivation of $V O$ and $O V$ 181-218.

Bates, Douglas, Martin Mächler, Ben Bolker \& Steve Walker. 2015. Fitting linear mixed-effects models using lme4. Journal of Statistical Software 67(1). 1-48. http://dx.doi.org/10.18637/jss.v067.i01.

Bermel, Neil \& Luděk Knittl. 2012. Corpus frequency and acceptability judgments: A study of morphosyntactic variants in czech .

Birner, Betty J \& Gregory Ward. 1998. Information status and noncanonical word order in english, vol. 40. John Benjamins Publishing.

Boersma, Paul \& David Weenink. 2013. Praat: doing phonetics by computer. 2013. Available form: URL: http://www. fon. hum. uva. nl/praat .

Bowern, Claire. 2008. Bardi arguments: referentiality, agreement, and omission in bardi discourse. Discourse and grammar in Australian languages. Amsterdam .

Cowart, W. 1997. Experimental syntax: applying objective methods to sentence judgements. Sage Publications. https://books.google.com/books?id= 10liAAAAMAAJ.

Dahlstrom, Amy. 2003. Focus constructions in meskwaki (fox). In The proceedings of the lfg'03 conference. 144. 
Dryer, Matthew S. 2007. Word order. Language typology and syntactic description 1. 61-131.

Dryer, Matthew S. 2013. Order of subject, object and verb. In Matthew S. Dryer \& Martin Haspelmath (eds.), The world atlas of language structures online, Leipzig: Max Planck Institute for Evolutionary Anthropology. https://wals.info/chapter/81.

Dunn, M, S J Greenhill, S C Levinson \& R D Gray. 2011. Evolved structure of language shows lineage-specific trends in word-order universals. $\mathrm{Na}$ ture 473(7345). 79-82. http://dx.doi.org/10.1038/nature09923. http: //www.ncbi.nlm.nih.gov/pubmed/21490599.

Enfield, Nick J. 2009. Case relations in Lao, a radically isolating language. In Andrej L. Malchukov \& Andrew Spencer (eds.), The oxford handbook of case, chap. 57. Oxford University Press.

Erteschik-Shir, Nomi. 1997. The dynamics of focus structure. Cambridge University Press.

Fanselow, Gilbert. 2003. Free Constituent Order: A Minimalist Interface Account. Folia Linguistica 37(1-2). 1-33.

Fedzechkina, Maryia, Elissa L Newport \& T Florian Jaeger. 2017. Balancing effort and information transmission during language acquisition: Evidence from word order and case marking. Cognitive science 41(2). 416446.

Fortescue, Michael. 1993. Eskimo word order variation and its contactinduced perturbation. Journal of Linguistics 29. 1-24.

Gil, David. 2005. Isolating-monocategorial-associational language. Handbook of Categorization in Cognitive Science 347-379.

Givón, Talmy. 2014. On understanding grammar. Academic Press.

Goldin-Meadow, Susan, Wing Chee So, Aslı Özyürek \& Carolyn Mylander. 2008. The natural order of events: How speakers of different languages represent events nonverbally. Proceedings of the National Academy of Sciences .

Gregory, Michelle L \& Laura A Michaelis. 2001. Topicalization and leftdislocation: A functional opposition revisited. Journal of pragmatics 33(11). 1665-1706.

Hale, Kenneth. 1983. Walpiri and the grammar of nonconfigurational languages. Natural Language and Linguistic Theory 1. 5-47. http://dx.doi. org/10.1007/BF00210374.

Hale, Kenneth. 1992. Basic word order in two "free word order" languages. Pragmatics of word order flexibility 63-82.

Hall, Matthew L. 2012. Keeping the hands in mind: what elicited pantomime reveals about language structure. La Jolla, California: University of Califor- 
nia, San Diego dissertation. http://dx.doi.org/10.1300/J122v22n03_06. Harris, Alice C \& Lyle Campbell. 1995. Historical syntax in cross-linguistic perspective, vol. 74. Cambridge University Press.

Herring, Susan. 1994. Postverbal Position in Tamil. In Miriam Butt, Tracy Holloway King \& Gillian Ramchand (eds.), Theoretical perspectives on word order in south asian languages, Stanford: Center for the Study of Language and Information.

Jackendoff, Ray. 1972. Semantic interpretation in generative grammar. Cambridge: MIT Press.

Jayaseelan, K A. 2008. Topic, Focus, and Adverb Positions in Clause Structure. Nanzan Linguistics 4. 1-26. http://www.ic.nanzan-u.ac.jp/ LINGUISTICS/publication/pdf/NL4-3-jayaseelan.pdf.

Kaiser, Elsi \& John C. Trueswell. 2004. The role of discourse context in the processing of a flexible word-order language. Cognition 94(2). 113-147. http://dx.doi.org/10.1016/j.cognition.2004.01.002.

Karimi, Simin. 2008. Scrambling. Language and Linguistics Compass 2(6). 1271-1293. http://dx.doi.org/10.1111/j.1749-818X.2008.00095. x. http://doi.wiley.com/10.1111/j.1749-818X.2008.00095.x.

Kerala Department of Education. 2011. Kerala Department of Education Statistical Report. Tech. rep. http://www.education.kerala.gov. in/Downloads2011/Notifications/statitics/selected\%20educational\% 20statistics\%202010-11.pdf.

Kiparsky, Paul. 1996. The shift to head-initial vp in germanic. Studies in comparative Germanic syntax 2. 140-179.

Kluender, Robert \& Marta Kutas. 1993. Bridging the gap: Evidence from erps on the processing of unbounded dependencies. Journal of Cognitive Neuroscience 5(2). 196-214.

Kwon, Nayoung, Robert Kluender, Marta Kutas \& Maria Polinsky. 2013. Subject/object processing asymmetries in korean relative clauses: Evidence from erp data. Language 89(3). 537.

Langsford, Steven, Amy Perfors, Andrew T Hendrickson, Lauren A Kennedy \& Danielle J Navarro. 2018. Quantifying sentence acceptability measures: Reliability, bias, and variability. Glossa: a journal of general linguistics 3(1).

Leela, Maya. 2016. Early Acquisition of Word Order: Evidence from HindiUrdu and Malayalam: Universitat Autonoma de Barcelona dissertation.

Mithun, Marianne. 1992. Is basic word order universal. Pragmatics of word order flexibility 22. 15-61.

Mithun, Marianne. 1995. Morphological and prosodic forces shaping word order. Word order in discourse 30. 387. 
Miyamoto, Edson T \& Shoichi Takahashi. 2001. Sources of Difficulty in Processing Scrambling in Japanese. In M Nakayama (ed.), Sentence processing in east asian languages, 1-21. CSLI.

Miyamoto, Edson T \& Shoichi Takahashi. 2004. Filler-gap dependencies in the processing of scrambling in japanese. Language and Linguistics 5(1). 153-166.

Mohanan, K P. 1982. Mohanan, K. P. 1982. Grammatical Relations and Clause Structure in Malayalam . In Joan Bresnan (ed.), The mental representation of grammatical relations, MIT Press.

Namboodiripad, Savithry. 2017. An experimental approach to variation and variability in constituent order: UC San Diego dissertation.

Namboodiripad, Savithry, Dayoung Kim \& Gyeongnam Kim. 2019. English dominant korean speakers show reduced flexibility in constituent order. Proceedings of CLS 53.

Nariyama, Shigeko. 2004. Subject ellipsis in english. Journal of Pragmatics 36(2). 237-264.

Newmeyer, Frederick J. 2000. On the reconstruction of 'proto-world'word order. The evolutionary emergence of language: Social function and the origins of linguistic form 372-388.

Nichols, Johanna. 1992. Linguistic diversity in space and time. University of Chicago Press.

Nordlinger, Rachel. 2006. Spearing the emu drinking: Subordination and the adjoined relative clause in wambaya. Australian Journal of Linguistics 26(1). 5-29.

Payne, Doris L. 2013. The pragmatics of word order: typological dimensions of verb initial languages, vol. 7. Walter de Gruyter.

Prince, Ellen F. 1988. On pragmatic change: the borrowing of discourse functions. Journal of pragmatics 12(5-6). 505-518.

Quakenbush, J Stephen. 1992. Word order and discourse type: An austronesian example. Pragmatics of word order flexibility. Amsterdam: Benjamins 279-304.

Sag, Ivan A \& Janet D Fodor. 1994. Extraction without traces. In West coast conference on formal linguistics, vol. 13. 365-384.

Salzmann, Martin David. 2004. Theoretical Approaches to Locative Inversion: University of Zurich dissertation. http://www.martinsalzmann. com/files/salzmann-loc-inv-distr04-01.pdf.

Siewierska, Anna \& Ludmila Uhlirova. 1998. An overview of word order in slavic languages. Empirical approaches to language typology 20. 105-150.

Šimík, Radek \& Marta Wierzba. 2015. The role of givenness, presupposition, and prosody in czech word order: An experimental study. Semantics and 
Pragmatics 8. 3-1.

Sinnemäki, Kaius. 2011. Language universals and linguistic complexity Three case studies in core argument marking. Helsinki, Finland: University of Helsinki dissertation.

Swartz, Stephen M. 1988. Pragmatic structure and word order in warlpiri, vol. 71 151-166 (Pacific Linguistics, Series A) Canberra: Australian National University.

Thomason, Sarah Grey. 2003. Contact as a source of language change. The handbook of historical linguistics 687-712.

Thomason, Sarah Grey \& Terrence Kaufman. 1988. Language contact, creolization, and genetic linguistics, vol. 19. University of California, Press.

Vasishth, Shravan. 2002. Working Memory in Sentence Comprehension: Processing Hindi Center Embeddings: The Ohio State University dissertation.

Weskott, Thomas \& Gilbert Fanselow. 2011. On the Informativity of Different Measures of Linguistic Acceptability . Language 87. 1-61.

Yasunaga, Daichi, Masataka Yano, Yoshiho Yasugi \& Masatoshi Koizumi. 2015. Is the subject-before-object preference universal? an event-related potential study in the kaqchikel mayan language. Language, Cognition and Neuroscience 30(9). 1209-1229.

Zaslansky, Matthew \& Savithry Namboodiripad. 2019. Syntactic flexibility in the djar dialect of avar: Experimental evidence from basic constituent order. Paper presented at Linguistic Forum 2019: Indigenous languages of Russia and beyond. 